\title{
P. ŠULEK
}

\section{A HYDRO POWER SYSTEM OPERATION USING GENETIC ALGORITHMS AND MIXED-INTEGER NONLINEAR PROGRAMMING}

\section{ABSTRACT}

This paper proposes a new hybrid optimization method for solving a hydrothermal coordination problem. In general, the problem is decomposed into smaller hydro and thermal sub-problems which are solved separately. The hydro sub-problem is solved by the peak shaving method using the proposed hybrid optimization method. It combines genetic algorithms with the traditional numerical optimization method. The hybrid method has been applied to a real hydrothermal system, i.e., the Slovak power system. The results have proved the efficiency of the proposed method.

\section{Peter ŠULEK}

email: peter.sulek@stuba.sk

Research field: hydraulic engineering, water structures, hydro power engineering.

Address: Department of Hydraulic Engineering, Faculty of Civil Engineering, Slovak University of Technology, Radlinského 11, 81368 Bratislava

\section{KEY WORDS}

- Hydro plant,

- hydrothermal coordination problem,

- peak shaving method,

- genetic algorithm,

- hybrid optimization,

- mixed-integer nonlinear programming

\section{INTRODUCTION}

The efficient scheduling of available energy resources for satisfying load demands has become an important task in modern power systems. For hydrothermal systems, the limited energy storage capability of water reservoirs, makes solving load demand problems a more difficult job than for pure systems. The hydrothermal generation-scheduling problem, which is also called the hydrothermal coordination problem, is a non-linear problem with a high degree of dimensionality, continuous and discrete variables and a non-explicit objective function with many constraints. The solution of the problem has been approached by conventional (traditional) or heuristic optimization techniques. The use of both approaches is often associated with difficulties. The article describes the possibility of solving this problem by a combination of both the numerical and heuristic approaches.

\section{MATERIALS AND METHODS}

The objective of hydrothermal coordination (HTC) is to determine the optimal operating schedule of thermal units and hydro plants that minimizes the system's total operating cost during a scheduling horizon, which is subject to many system constraints. The HTC problem can be formulated as a mathematical optimization problem as follows:

$$
\begin{aligned}
C=\sum_{i=1}^{T} \sum_{j=1}^{N T} C C_{j, i}\left(P_{T j, i}\right) \rightarrow \min \\
C-\text { total system operating cost, } \\
i-\text { time interval (hour) index, } \\
T-\text { total number of time intervals (scheduling horizon), } \\
j-\text { thermal unit index, } \\
N T-\text { number of thermal units, }
\end{aligned}
$$


$C C_{i}()$ - fuel cost function of thermal unit $j$ during hour $i$, a function of $P_{T j, i}$

$P_{T j, i}$ - power output of thermal unit $j$ during hour $i$,

$$
\sum_{j=1}^{N T} P_{T j, i}=\operatorname{Dem}_{i}-\sum_{k=1}^{N H} P_{k, i}
$$

$D e m_{i}$ - total load demand of hydrothermal power system during hour $i$,

$\mathrm{NH}$ - number of hydro plants,

$P_{k, i}$ - power output of hydro plant $k$ during hour $i$,

$k$ - hydro plant index.

It has been assumed that hydro plants have zero operating costs.

The optimal scheduling of a hydrothermal power system is a complex mixed-integer, non-linear optimization problem. The solution of the above problem has been approached by many optimization techniques such as peak shaving (Simopoulos, et al., 2007; Wu, et al., 1989; Wu, et al., 1991); linear programming (Seewald, 1997; Šulek, Dušička, 2006); dynamic programming (Tang, Luh, 1995; Yang, Chen, 1989); mixed-integer programming (Chang, et al., 2001; Li, et al., 1993) and genetic algorithms (Gil, et al., 2003; Zoumas, et al., 2004). Many of the above-mentioned methods make various simplifying assumptions in order to reduce the complexity of the optimization problem which arises from simultaneous consideration of thermal and hydro plants. Oftentimes, the original problem is decomposed into smaller hydro and thermal sub-problems, which are solved independently. The decomposition of the problem allows for the detailed formulation of each subproblem without making any major simplifying assumptions.

A typical example of the decomposition method is the peak shaving (PS) method. The PS method is based on the idea that the hydroelectric generation should be allocated in the higher part of the system's load curve, which corresponds to the system's peak loads (Fig.1). The solution of the hydro sub-problem by the PS method is described below.

\subsection{Hydro Sub-problem Formulation}

The hydro sub-problem can be defined by the following function:

$$
\begin{aligned}
& F=\sum_{i=1}^{T}\left(\operatorname{Dem}_{i}-\sum_{k=1}^{N H}\left(S T_{k, i} \cdot P_{k, i}\right)\right)^{2} \\
& =\sum_{i=1}^{T}\left(\operatorname{Dem}_{i}-\sum_{k=1}^{N H}\left(S T_{k, i} \cdot 9,81 \cdot Q_{k, i} \cdot H_{k, i} \cdot \eta_{k, i} \cdot 10^{-3}\right)\right)^{2} \rightarrow \min \\
& \quad \forall k \in[1, N H] ; \forall i \in[1, T]
\end{aligned}
$$

subject to

- hydro plant operation limits $\forall k \in[1, N H], \forall i \in[1, T]$ $S T_{k, i} \cdot\left(P_{\min , k}+{ }^{R S V-} P_{k, i}\right)<=P_{k, i}<=S T_{k, i} \cdot\left(P_{\max , k^{-}}{ }^{R S V+} P_{k, i}\right)$ $S T_{k, i} \cdot\left(Q_{\min , k}+{ }^{R S V}-Q_{k, i}\right)<=Q_{k, i}<=S T_{k, i} \cdot\left(Q_{\max , k}-{ }^{R S V+} Q_{k, i}\right)$ - reservoir storage capacity limits $\forall k \in[1, N H], \forall i \in[1, T]$

$V_{\min , k}<=V_{k, i}<=V_{\max , k}$

$V_{k, 0}=V_{i n, k}$ and $V_{k, T}=V_{f i n, k}$

where

$S T_{k, i}$ is operating state of hydro plant (variables); (1 - if the plant is $\mathrm{ON}$ and 0 - if the plant is OFF),

$P_{k, i}-$ power output of hydro plant [MW]; $P_{k, i}=9,81 \cdot Q_{k, i} \cdot H_{k, i} \cdot \eta_{k, i} \cdot 10^{-3}$

$Q_{k, i}$ - discharge of hydro plant [ $\left.\mathrm{m}^{3} / \mathrm{s}\right]$ (variables),

$H_{k, i}$ - average net head of hydro plant [m],

$\eta_{k, i}$ - efficiency of hydro plant [-]; $\eta_{k, i}$ is a function of $Q_{k, i}$ and $H_{k, i}$,

$P_{\min , k}-$ minimum power output of hydro plant $[\mathrm{MW}]$,
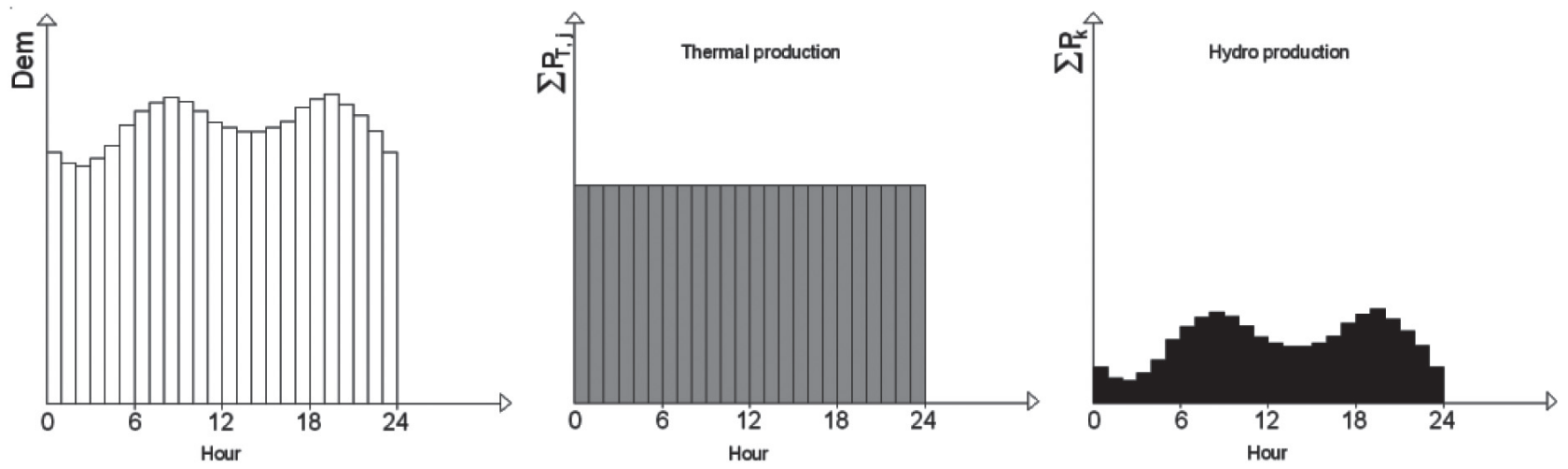

Fig. 1 Peak-shaved load curve. 
$P_{\max , k}-$ maximum power output of hydro plant [MW],

${ }^{R S V}{ }^{+} P_{k, i}-$ plus spinning reserve of hydro plant [MW],

${ }^{R S V}-P_{k, i}-$ minus spinning reserve of hydro plant [MW],

$Q_{\text {min, } k}$ - minimum discharge of hydro plant $\left[\mathrm{m}^{3} / \mathrm{s}\right]$,

$Q_{\max , k}$ - maximum discharge of hydro plant $\left[\mathrm{m}^{3} / \mathrm{s}\right]$,

${ }^{R S V}{ }^{\max } Q_{k, i}$ - discharge equivalent of the plus spinning reserve of hydro plant [MW],

${ }^{R S V}{ }^{2} Q_{k, i}$ - discharge equivalent of the minus spinning reserve of hydro plant [MW],

$V_{\text {min,k }}$ - reservoir's minimum storage volume $\left[\mathrm{m}^{3}\right]$,

$V_{\max , k}-$ reservoir's maximum storage volume $\left[\mathrm{m}^{3}\right]$.

$V_{i n, k}-$ reservoir's initial storage volume $\left[\mathrm{m}^{3}\right]$,

$V_{f i n, k}-$ reservoir's final (target) storage volume $\left[\mathrm{m}^{3}\right]$.

The water balance for each reservoir of a hydro plant $k$ during hour $i$ is given by

$V_{k, i}=V_{k, i-1}-3600 \cdot Q_{k, i}+I_{k, i}$

where

$V_{k, i}-$ reservoir storage volume at the end of an hour $i\left[\mathrm{~m}^{3}\right]$,

$I_{k, i}$ - inflow rate including the evaporation losses, leakage and other non-energy withdrawals $\left[\mathrm{m}^{3}\right]$.

The solution of problem (2) is represented by matrix $S$.

$S=\left[\begin{array}{cccc|cccc}Q_{1,1} & Q_{1,2} & \ldots \ldots & Q_{1, T} & S T_{1,1} & S T_{1,2} & \ldots \ldots & S T_{1, T} \\ Q_{2,1} & Q_{2,2} & \ldots . & Q_{2, T} & S T_{2,1} & S T_{2,2} & \ldots \ldots & S T_{2, T} \\ : & : & \ldots . & : & : & : & \ldots \ldots & : \\ Q_{N H, 1} & Q_{N H, 2} & \ldots . . & Q_{N H, T} & S T_{N H, 1} & S T_{N H, 2} & \ldots \ldots & S T_{N H, T}\end{array}\right] t$

\subsection{Hydro Sub-Problem Solution Methods}

The optimization problem (2) with limits (3)-(6) is a complex mixed-integer, non-linear optimization problem with non-linear constraints. The problem is all the more complicated if the water travel time between the cascaded hydro plants is also taken into account. Consequently, the course of the objective function is a complexity with many local extremes.

\subsubsection{Traditional numerical optimization methods}

The solution of the above-mentioned problem using traditional numerical optimization methods (e.g., non-linear programming, dynamic programming) is associated with many difficulties (e.g., "the curse of dimensionality"). Most of the traditional methods are unable to produce a near-optimal solution for this kind of problem. The problem must be decomposed into several smaller problems to decrease the number of variables. The objective function $F$ is decomposed into partial functions $F_{K}$ for each hydro plant. It can be written as:

$$
F=\sum_{k=1}^{N H} F_{K}=\sum_{k=1}^{N H} \sum_{i=1}^{T}\left(\left(\operatorname{Dem}_{i}-\sum_{k=1}^{k-1}\left(S T_{k-1, i} \cdot P_{k-1, i}\right)\right)-S T_{k, i} \cdot P_{k, i}\right)^{2} \rightarrow \min
$$

The solution of problem (8) is represented by vectors $\boldsymbol{s}_{\boldsymbol{k}}$.

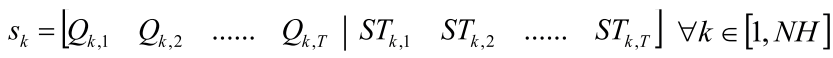

The value of the objective function $F$ is obtained by the sequential (downstream) solution of the sub-objective functions $F_{K}$. That is how the number of variables is decreased from $2 * T^{*} N H$ to $2^{*} T$. The sub-objective functions $F_{K}$ are solved using traditional numerical optimization methods for a mixed-integer nonlinear problem (MINLP). However, in many cases the value of the objective function $F$ (as the sum of the values $F_{K}$ ) may not be the global extreme function $F$.

\subsubsection{Heuristic optimization methods}

In addition to traditional numerical optimization methods, heuristic optimization methods (e.g., local search, tabu search, harmony search, simulated annealing, genetic algorithms) are used. Significant representatives of the heuristic methods are genetic algorithms (GA). GA are searching algorithms based on the mechanics of natural selection and natural genetics. A detailed description of the method can be found in (Goldberg 1989).

To use a GA, the objective function of the hydro sub-problem (2) must be modified to

$$
F=\sum_{i=1}^{T}\left(\operatorname{Dem}_{i}-\sum_{k=1}^{N H} S T_{k, i} \cdot P_{k, i}\right)^{2}+\sum_{k=1}^{N H} \operatorname{pen}_{1}\left(V_{k, T}, V_{f i n, k}\right)+\sum_{k=1}^{N H} \sum_{i=1}^{T-1} \operatorname{pen}_{2}\left(V_{k, i}, V_{\min , k}\right)
$$

$+\sum_{k=1}^{N H} \sum_{i=1}^{T} \operatorname{pen}_{3}\left(S T_{k, i}, P_{k, i}, P_{\max , k}\right)+\sum_{k=1}^{N H} \sum_{i=1}^{T} p e n_{4}\left(S T_{k, i}, P_{k, i}, P_{\min , k}\right)$

$+\sum_{k=1}^{N H} \sum_{i=1}^{T} \operatorname{pen}_{5}\left(S T_{k, i}, Q_{k, i}, Q_{\max , k}\right)+\sum_{k=1}^{N H} \sum_{i=1}^{T} \operatorname{pen}_{6}\left(S T_{k, i}, Q_{k, i}, Q_{\min , k}\right)$

$\rightarrow \min , \forall k \in[1, N H] ; \forall i \in[1, T]$

The pen1(), pen2(), pen3(), pen4(), pen5(), pen6() are penalty functions.

$\operatorname{pen}_{1}\left(V_{k, T}, V_{f i n, k}\right)=\left\{\begin{array}{cc}K_{1}\left(V_{k, T}-V_{f i n, k}\right)^{2} & V_{k, T}<V_{f i n, k} \\ 0 & V_{k, T} \geq V_{f i n, k}\end{array}\right.$
$\operatorname{pen}_{2}\left(V_{k, T}, V_{\text {min }, k}\right)=\left\{\begin{array}{cc}K_{2}\left(V_{k, i}-V_{\min , k}\right)^{2} & V_{k, i}<V_{\min , i} \\ 0 & V_{k, i} \geq V_{\text {min }, i}\end{array}\right.$ 


$$
\begin{aligned}
& \operatorname{pen}_{3}\left(S T_{k, i} P_{k, i} P_{\max , k}\right)=\left\{\begin{array}{c}
\left.K_{3}\left[\left(P_{\max , k}-{ }^{R S V+} P_{k, i}\right)-S T_{k, i} \cdot P_{k, i}\right)\right]^{2} \\
0
\end{array}\right. \\
& S T_{k, i} \cdot P_{k, i}>\left(P_{\max , i}-{ }^{R S V+} P_{k, i}\right) \\
& S T_{k, i} \cdot P_{k, i} \leq\left(P_{\max , i}-{ }^{R S V+} P_{k, i}\right) \\
& \operatorname{pen}_{4}\left(S T_{k, i} P_{k, i}, P_{\min , k}\right)=\left\{\begin{array}{c}
K_{4}\left[\left(S T_{k, i} \cdot P_{k, i}-\left(P_{\min , k}+{ }^{R S V}-P_{k, i}\right)\right]^{2}\right. \\
0
\end{array}\right. \\
& S T_{k, i} \cdot P_{k, i}<\left(P_{\min , i}+{ }^{R S V-} P_{k, i}\right) \\
& S T_{k, i} \cdot P_{k, i} \geq\left(P_{\min , i}+{ }^{R S V} P_{k, i}\right) \\
& \operatorname{pen}_{5}\left(S T_{k, i}, Q_{k, i} Q_{\text {max }, k}\right)=\left\{\begin{array}{c}
\left.K_{5}\left[\left(Q_{\text {max }, k}-{ }^{R S V+} Q_{k, i}\right)-S T_{k, i} \cdot \mathrm{Q}_{k, i}\right)\right]^{2} \\
0
\end{array}\right. \\
& S T_{k, i} \cdot Q_{k, i}>\left(Q_{\max , i}-{ }^{R S V+} Q_{k, i}\right) \\
& S T_{k, i} \cdot Q_{k, i} \leq\left(Q_{\max , i}{ }^{R S V+} Q_{k, i}\right) \\
& \operatorname{pen}_{6}\left(S T_{k, i} Q_{k, i} Q_{\text {min }, k}\right)=\left\{\begin{array}{c}
K_{6}\left[\left(S T_{k, i} \cdot \mathrm{Q}_{k, i}-\left(Q_{\min , k}+{ }^{R S V-} Q_{k, i}\right)\right]^{2}\right. \\
0
\end{array}\right. \\
& S T_{k, i} \cdot Q_{k, i}<\left(Q_{\min , i}+{ }^{R S V}-Q_{k, i}\right) \\
& S T_{k, i} \cdot Q_{k, i} \geq\left(Q_{\min , i}+{ }^{R S V}-Q_{k, i}\right)
\end{aligned}
$$

where $K_{1}, K_{2}, K_{3}, K_{4}, K_{5}$ and $K_{6}$ are the weight factors of the penalty functions.

The solution of problem (9) is represented by the best chromosome ${ }^{F I N} \boldsymbol{S}$ from the final generation (the chromosome with the best fitness, fitness $=-F$ ). Despite many benefits (e.g., the non-explicit acceptability of the objective function), GA have a number of disadvantages:

- a high risk of being trapped in the local extreme of the $F$,

- it is relatively difficult to define the weight of the penalty functions.

Furthermore, we can describe the possibility of eliminating these disadvantages by using the proposed method.

\subsubsection{The proposed hybrid optimization methods}

According to (Reis, et al., 2006), one way to eliminate the disadvantages of a GA is a combination of genetic algorithms with traditional numerical optimization methods. The objective function (9) can be written in a stand-alone form (16) without any penalty functions.

$$
F=\sum_{i=1}^{T}\left(\operatorname{Dem}_{i}-\sum_{k=1}^{N H}\left(S T_{k, i} . P_{k, i}\right)\right)^{2} \rightarrow \min , \forall k \in[1, N H] ; \forall i \in[1, T]
$$

The fact that the GA searching space only includes feasible solutions $\left.\boldsymbol{S}=\left(Q_{k, i} \mid S T_{k, i}\right)_{T, N H}\right)$ is ensured by the numerical optimization methods, which are directly implanted in the fitness function. The chromosomes $\boldsymbol{S}$ are replaced with the chromosomes $\boldsymbol{w}=\left(w_{k, j}\right)_{T, N H}$. The $w_{k, i}$ value is the weight factor of the objective functions $f_{K}$.

$f_{k}=\sum_{i=1}^{T} w_{k, i} . S T_{k, i} \cdot P_{k, i} \rightarrow \max , \forall k \in[1, N H] ; \forall i \in[1, T]$

The optimization problem (17) with constraints (3)-(6) is solved using Branch-and-Bound method. If the matrix $\boldsymbol{F I N}_{\boldsymbol{w}}$ is the best chromosome from the final generation (the chromosome with the best fitness, fitness $=-F$ ), the solution of problem (16) is represented by matrix ${ }^{F I N} \boldsymbol{S}$. The block diagram of the proposed GA-MINLP hybrid optimization method (combining GA and the traditional numerical method for a mixed-integer nonlinear problem) is shown in Fig. 2

\section{RESULTS}

The proposed GA-MINLP hybrid method was applied to the HTC problem of the Slovak power system (operated by ENEL SE, Inc.). This hydrothermal system consists of 20 hydro plants (three of which are pumped-storage plants) and 2 thermal plants.

The hourly load demand system on September 20, 2010 is given in Table 1. System imports, small run-of-river hydro plants production and nuclear production have been subtracted from the actual load demand.

The configuration of the hydro system with the input data is presented in Fig. 4. It can be seen that two of the hydro plants are independent, but the rest are hydraulically coupled in a cascade. The computer code (developed in Visual Basic) has been designed to model a complex network of rivers with time delays between the hydro plants and reservoirs.

Tab. 1 Hourly load demand on September 20, 2010 [MW].

\begin{tabular}{|c|c|c|c|c|c|c|c|}
\hline Hour & Load & Hour & Load & Hour & Load & Hour & Load \\
\hline 1 & 731 & 7 & 781 & 13 & 991 & 19 & 1013 \\
\hline 2 & 720 & 8 & 831 & 14 & 969 & 20 & 1000 \\
\hline 3 & 720 & 9 & 881 & 15 & 954 & 21 & 950 \\
\hline 4 & 720 & 10 & 931 & 16 & 950 & 22 & 900 \\
\hline 5 & 720 & 11 & 980 & 17 & 951 & 23 & 850 \\
\hline 6 & 731 & 12 & 1002 & 18 & 964 & 24 & 801 \\
\hline
\end{tabular}




\section{IDOJLS JOUSSILL

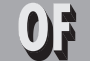

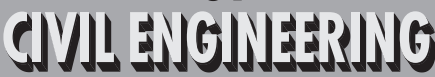

2012/1 PAGES $1-9$

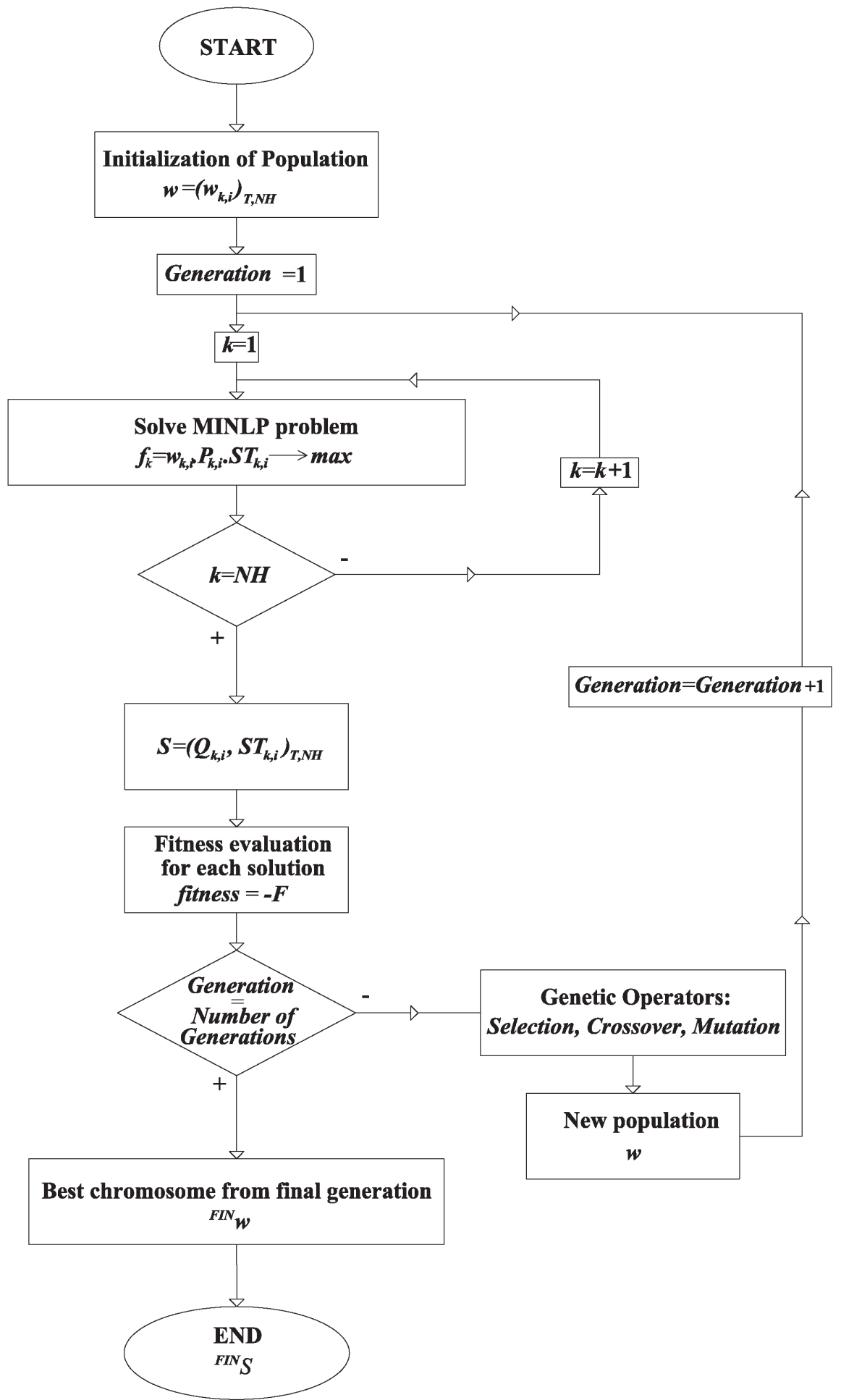

Fig. 2 Block diagram of the proposed GA-MINLP hybrid method. 


\section{SDOHASJODSTILL \\ of

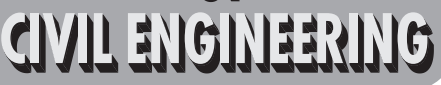

2012/1 PAGES $1-9$

The proposed hybrid approach solution was applied to the hydro sub-problem. The traditional numerical optimization with the MINLP Decomp decomposition (described in 2.2.1) was applied to the same hydro sub-problem too.

Table 2 summarizes the test parameters and results obtained from each method. The results of the GA-MINLP and MINLP Decomp are compared in terms of their minimum $F$ value. The difference in the $F$ value of the best GA-MINLP and MINLP Decomp runs was $0.12 \%$ (in favour of the GA-MINLP method). The decrease in the total operating costs of the system of the best GA-MINLP run could be determined by calculating the fuel cost function of the thermal units (not available).
Tab. 2 Test parameters and results.

\begin{tabular}{|c|c|c|c|}
\hline \multicolumn{2}{|l|}{ Method } & GA-MINLP & $\begin{array}{l}\text { MINLP } \\
\text { Decomp }\end{array}$ \\
\hline Number of HP & & 20 & \\
\hline \multicolumn{2}{|c|}{$\begin{array}{l}\text { Number of Variables (in one-step } \\
\text { of solution) }\end{array}$} & 576 & 48 \\
\hline \multicolumn{2}{|l|}{ Population size } & 50 & - \\
\hline \multicolumn{2}{|c|}{ Number of Generation } & 500 & - \\
\hline \multirow{3}{*}{ Minimum F Value } & Best run & $4,957,082$ & $4,963,015$ \\
\hline & Worst run & $5,395,882$ & - \\
\hline & \% Difference & 8.852 & - \\
\hline
\end{tabular}

GA-MINLP Hybrid Method

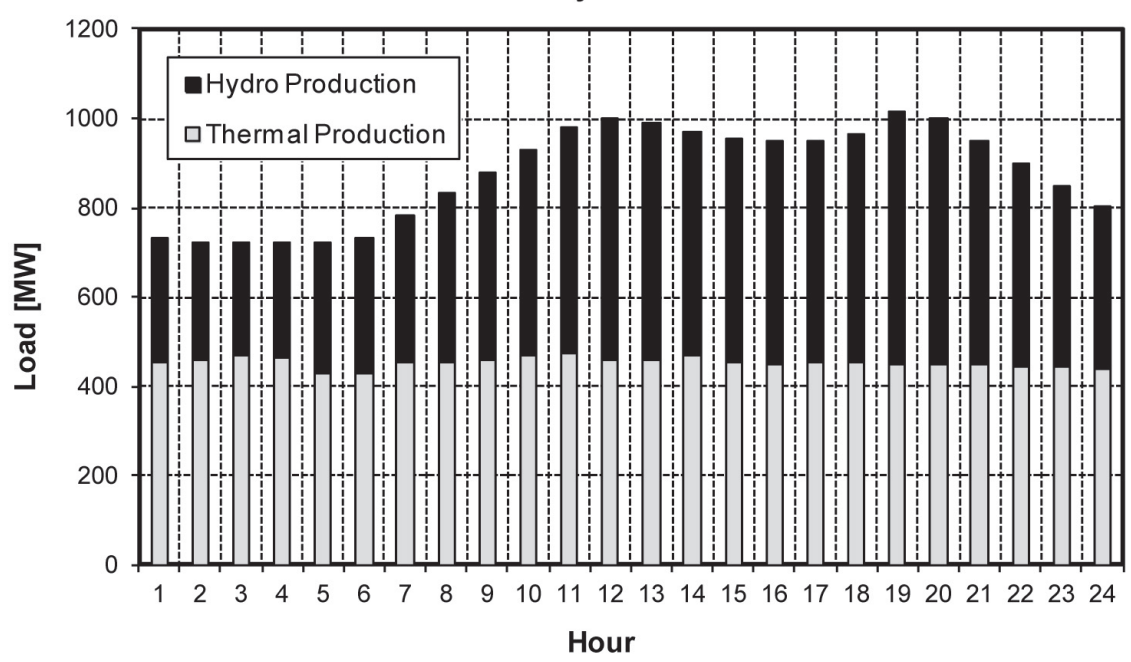

MINLP Decomp Method

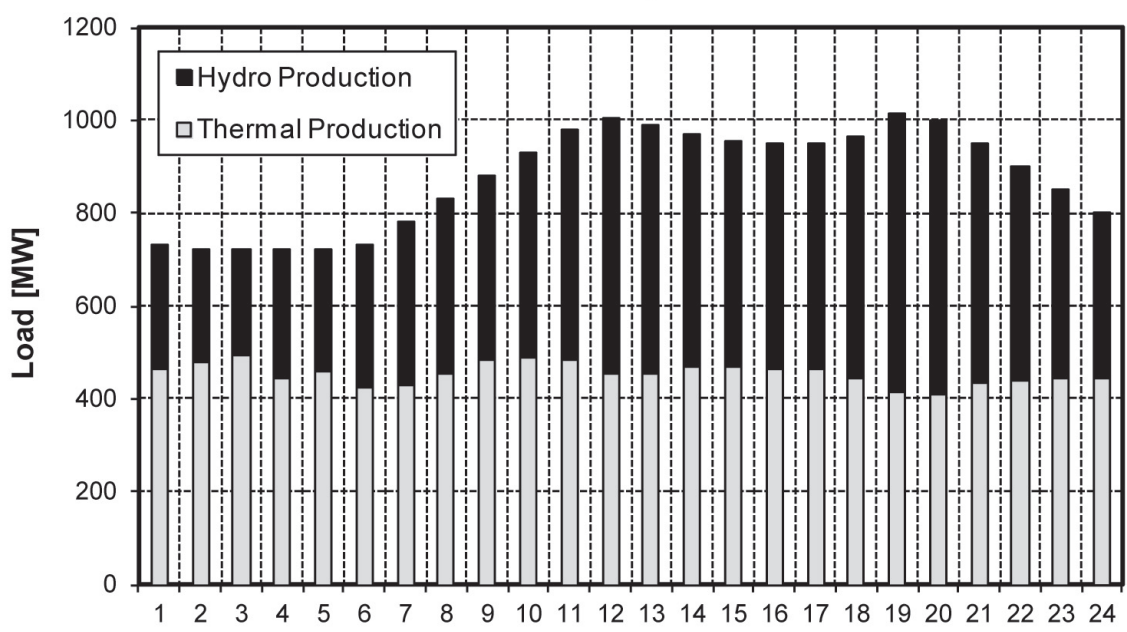

Hour

Fig. 3 Power generation from hydro and thermal plants. 


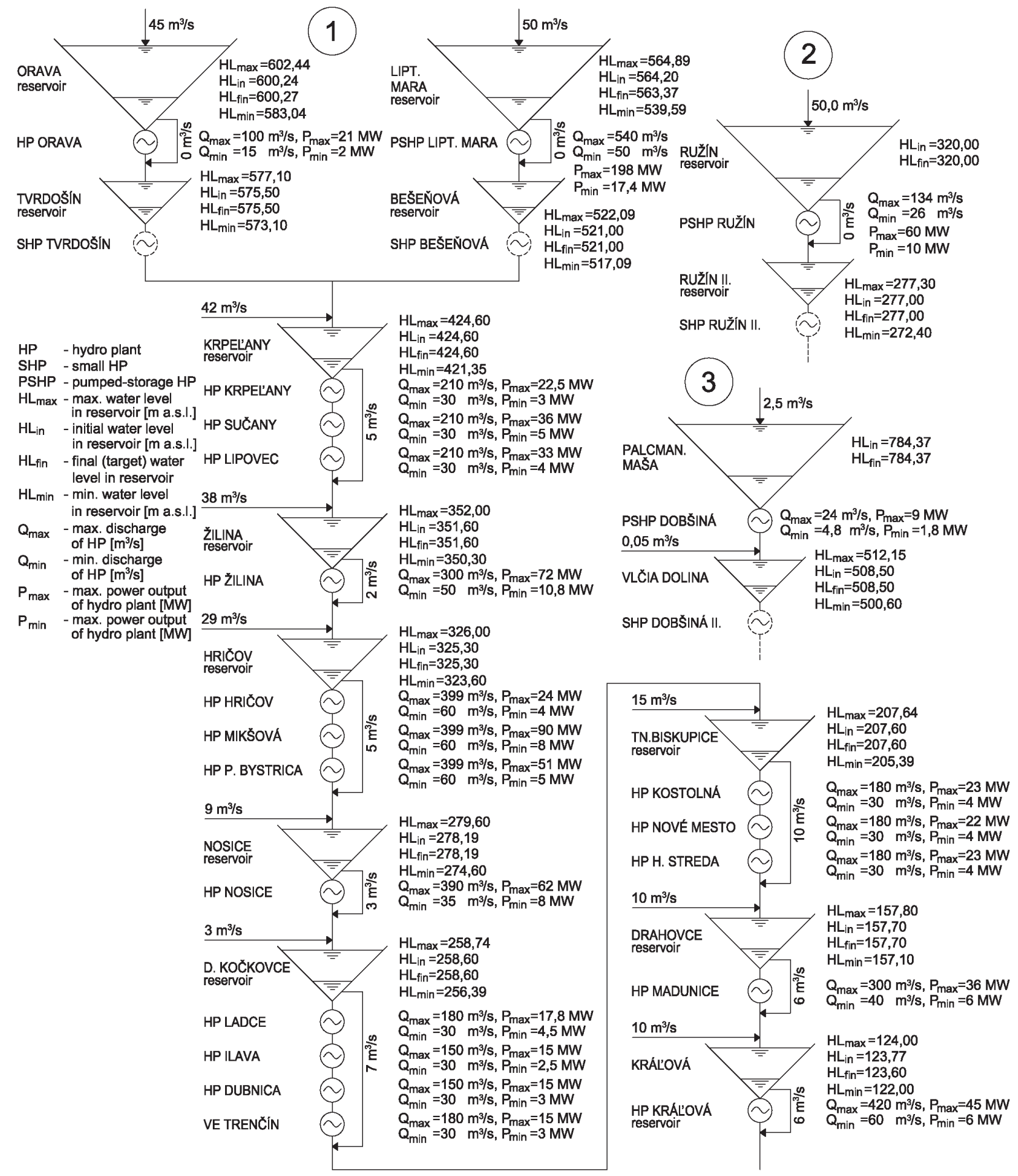

Fig. 4 Configuration of hydro system with input data from September 20, 2010. 
Fig. 3 illustrates the power production of the hydro and thermal plants solved using both approaches. As expected, the operation of the hydro plants focuses on the peak load hours, resulting in a peak shaved load curve which is supplied by the thermal units.

\section{CONCLUSION}

A hybrid method for the solution of a hydro sub-problem using a combination of GA and MINLP has been presented. The proposed method has been tested on a real power system, the
Slovak power system, consisting of 20 hydro plants and 2 thermal plants. The results prove the effectiveness of the method. The disadvantages of the GA-MINLP hybrid methods are still the remaining relatively "long" execution times and high demands on hardware equipment.

\section{Acknowledgements}

This paper was supported by the VEGA Grant agency under Contract No.1/0578/11 and the Slovak Research and Development Agency under Contract No. APVV-0680-10.

\section{REFERENCES}

[1] Čistý, M., Bajtek, Z. (2009): Hybrid method for the design of the water distribution systems. Journal of Hydrology and Hydromechanics. 57(2). SAP. Bratislava, 2009: pp. $130-141$

[2] Goldberg, D.E. (1989): Genetic Algorithms in Search. Optimization and Machine Learning. New York, AddisonWesley, 1989.

[3] Gil, E., Bustos, J., Rudnick, H. (2003): Short-term hydrothermal generation scheduling model using a genetic algorithm. IEEE Trans Power Syst. 18(4), 2003: pp. 1256-64.

[4] Heredia, F.J., Nabona, N. (1995): Optimum short-term hydrothermal scheduling with spinning reserve through network flows. IEEE Trans Power Syst. 10(3), 1995: pp. 1642-51.

[5] Chang, G.W., Aganagic, M., Waight, J.G., Medina, J., Burton, T., Reeves, S. (2001): Experiences with mixed integer linear programming based approaches on short-term hydro scheduling. IEEE Trans Power Syst. 16(4), 2001: pp. 743-9.

[6] Li, C., Jap, P.J., Streiffert, D.L. (1993): Implementation of network flow programming to the hydrothermal coordination in an energy management system. IEEE Trans Power Syst. 8(3), 1993: pp. 1045-53.

[7] Nacházel, K., Toman, M. (1995): Perspective of the genetic algorithms in the theory of reservoirs water resources systems. Journal of Hydrology and Hydromechanics. 43(3), 1995. SAP. Bratislava.
[8] Nilsson, O., Sjelvgren, D. (1996): Mixed-integer programming applied to short-term planning of a hydro-thermal system. IEEE Trans Power Syst. 11(1), 1996: pp. 281-6.

[9] Reis, L.F.R., Bessler, F.T., Walters, G.A., Savic, D. (2006): Water Supply Reservoir Operation by Combined Genetic Algorithm - Linear Programming Approach. Water Resources Management. 20, 2006: pp. 227-255.

[10] Seewald, V. (1997): Riadenie hydroenergetického systému SE, a.s. (Operating SE, Inc. hydro power system). Odborný časopis pre elektroenergetiku a energetiku. Bratislava. 1(3), 1997: pp. 17-20. (In Slovak)

[11] Šulek, P., Dušička, P. (2006): Návrh algoritmov hydromodelovania pre SW Model prevádzky hydro systému SE, a.s. (The proposed hydromodeling algorithms for SW operating model of SE, Inc. hydro power system). Technical documentation. STU Bratislava, 2006. (Slovak)

[12] Simopoulos, D., Kavatza, S., Vournas, C. (2007): An enhanced peak shaving method for short term hydrothermal scheduling. Energy Conversion and Management 48, 2007: pp. 3018-3024

[13] Tang, J., Luh, P.B. (1995): Hydrothermal scheduling via extended differential dynamic programming and mixed coordination. IEEE Trans Power Syst. 10(4), 1995: pp. 2021-8.

[14] Wu, R.N., Lee, T.H., Hill, E.F. (1989): An investigation of the accuracy and the characteristics of the peak-shaving method applied to production cost calculations. IEEE Trans Power Syst, 4(3), 1989: pp. 1043-9. 


\section{IDOJLS JOUSSILL \\ $0 \overrightarrow{5}$

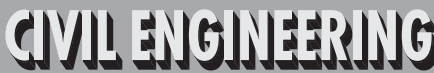

2012/1 PAGES $1-9$

\section{REFERENCES}

[15] Wu, R.N., Lee, T.H., Hill, E.F. (1991): Effect of interchange on short-term hydrothermal scheduling. IEEE Trans Power Syst. 6(3), 1991: pp. 1217-23.

[16] Yang, J., Chen, N. (1989): Short term hydrothermal coordination using multipass dynamic programming. IEEE Trans Power Syst. 4(3), 1989: pp. 1050-6.
[17] Zoumas, C.E., Bakirtzis, A.G., Theocharis, J.B., Petridis, V (2004): A genetic algorithm solution approach to the hydrothermal coordination problem. IEEE Trans Power Syst. 19(2), 2004: pp. 1356-64.

[18] NeuroDimension, Inc.: Genetic Server, http://www.nd.com

[19] Frontline Systems, Inc.: Frontline Systems Solver Engines, http://www.solver.com 